\title{
Omega-3 and -6 Fatty Acid Intake and Colorectal Cancer Risk in Swedish Women's Lifestyle and Health Cohort
}

\author{
Aesun Shin, MD, $\mathrm{PhD}^{1,2}$ \\ Sooyoung Cho, MS 1,2 \\ Sven Sandin, $\mathrm{PhD}^{3,4,5}$ \\ Marie Lof, $\mathrm{PhD}$,7 \\ Moon Young $\mathbf{O h}, \mathrm{MD}^{8}$ \\ Elisabete Weiderpass, MD, PhD ${ }^{9}$
}

\begin{abstract}
${ }^{1}$ Department of Preventive Medicine, Seoul National University College of Medicine, Seoul, ${ }^{2}$ Cancer Research Institute, Seoul National University, Seoul, Korea, ${ }^{3}$ Department of Medical Epidemiology and Biostatistics, Karolinska Institutet, Stockholm, Sweden, ${ }^{4}$ Department of Psychiatry, Icahn School of Medicine at Mount Sinai, New York, NY, ${ }^{5}$ Seaver Autism Center for Research and Treatment at Mount Sinai, New York, NY, USA, ${ }^{6}$ Department of Biosciences and Nutrition, Karolinska Institutet, Stockholm, ${ }^{7}$ Department of Health, Medicine and Caring Sciences, Linköping University, Linköping, Sweden, ${ }^{8}$ Department of Surgery, Seoul National University Hospital, Seoul, Korea, ${ }^{9}$ International Agency for Research on Cancer, Lyon, France
\end{abstract}

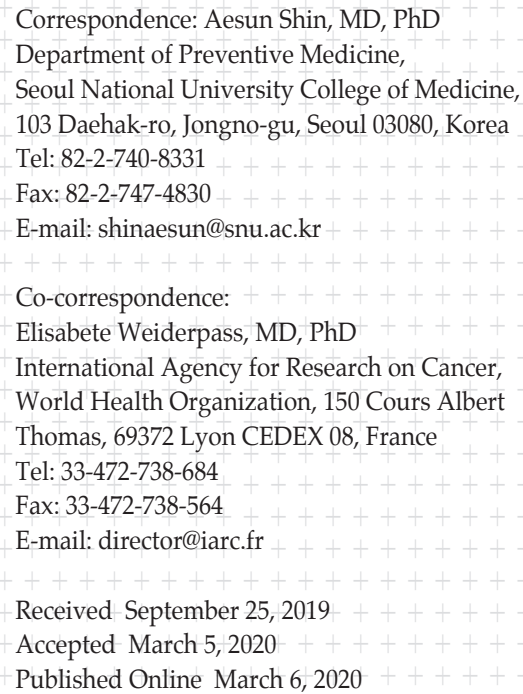

\section{Purpose}

We aimed to assess the association between the dietary intake of fish-derived omega-3 polyunsaturated fatty acids and the risk of colorectal cancer among Swedish women.

\section{Materials and Methods}

A total of 48,233 women with information on dietary intake were included in the analysis. Participants were followed for incident colorectal cancer until 31 December 2012. Cox proportional hazard models were used to assess the association between baseline fatty acid intake and colorectal cancer risk. All analyses were stratified by colon and rectal cancers.

\section{Results}

During a median of 21.3 years of follow-up, a total of 344 colorectal cancer cases were ascertained. Although there was no overall association between omega-3 fatty acid intake and colorectal cancer risk, high intake of fish-derived docosahexaenoic acid was associated with reduced risk of rectal cancer (hazard ratios for the third and the highest quartiles were 0.59 (95\% confidence interval [Cl], 0.37 to 0.96$)$ and 0.62 (95\% $\mathrm{Cl}, 0.39$ to 0.98$)$, respectively).

\section{Conclusion}

In conclusion, we found only limited support for an association between omega-3 polyunsaturated fatty acids and colorectal cancer in a large Swedish cohort of middle-aged women.

\author{
Key words \\ Colorectal neoplasms, Diet, Prevention
}




\section{Introduction}

Despite the anticarcinogenic effects of omega (n)-3 fatty acids, especially long-chain polyunsaturated fatty acids (PUFAs), demonstrated in animal studies [1], epidemiological studies have not shown consistent results to support their protective effect on cancers. Meta-analyses of prospective studies show no overall association between n-3 fatty acid intake and colorectal cancer $[2,3]$ and marginally significant inverse association between fish intake, which is the most important dietary source of n-3 fatty acids, and colorectal cancer risk $[3,4]$. However, it is noteworthy that the protective effect of marine n-3 PUFAs is more prominent when the study population is followed for longer periods [4]. Although not significant, a nonlinear inverse dose-response association was observed at up to $1 \mathrm{~g}$ / day of murine n-3 PUFA intake $[2,3]$. In addition, the association differs by sex and anatomical subsites of colorectal cancer [5].

One previous study from the Swedish Mammography Cohort, which used similar methods to measure dietary fatty acids, showed no association between fatty acid intake and colorectal cancer risk during up to 11 years of follow-up [6]. Here, we utilized the Swedish Women's Lifestyle and Health (WLH) cohort, which consisted of women aged 29-49 and followed for more than 20 years, to clarify the potential beneficial effect of n-3 PUFAs on colorectal cancer risk. The primary study objective was to examine the association between the dietary intake of fish-derived n-3 PUFAs (eicosapentaenoic acid and docosahexaenoic acid [DHA]) and the risk of colorectal cancer in the WLH cohort. Additionally, we also included total n-3 and n-6 fatty acid intake. Possible differences in the association by colorectal cancer subsites were addressed.

\section{Materials and Methods}

\section{Study population}

The study population included participants in the Swedish WLH cohort (https:// ki.se/en/meb/womens-lifestyle-andhealth) that answered the baseline (1991-1992) questionnaire [7].

Among 49,258 participants, those who were diagnosed with colorectal cancer before enrollment $(n=15)$, who emigrated without reimmigration $(\mathrm{n}=34)$, and who were outside the 1st and 99th percentiles of energy intake $(n=986)$ were excluded. Finally, 48,233 participants were included in the analysis.
Dietary habits were collected through a validated food-frequency questionnaire (FFQ) that covered 80 food items and beverages. The detailed method used to estimate the dietary intake of n-3/n-6 fatty acids and total calories was described in a previous study [8]. Information on demographic and lifestyle factors, weight, and height was also collected from a self-administered questionnaire [7].

Colorectal cancer incidence was ascertained from the Swedish Cancer Register by using the International Classification of Diseases, 9th revision (ICD-9) codes 153 and 154.

The dietary intake of n-3/n- 6 fatty acids was categorized into quartiles (lowest 25\%, 25-50\%, 50-75\%, and highest $25 \%$ ). Potential confounders were selected based on a previous study [9]. Potential confounders were categorized as follows, as in previous publications describing this cohort $[9,10]$ : body mass index $\left(\mathrm{kg} / \mathrm{m}^{2} ;<25,25-30, \geq 30\right.$, or missing), education (years; $\leq 10,11-13$, or $>13$ ), smoking history (never or ever), and alcohol intake (g/day; $<5,5-25, \geq 25$ ). Due to the relatively high percentage of missing data, the intake frequency of meat $(n=13,088)$ and sausage $(n=19,030)$ were not considered in the multivariate analysis. Although physical activity is an important protective factor for colorectal cancer, the questionnaire item for physical activity only addressed subjective activity level rather than frequency or intensity; therefore, we did not include this variable as a confounder.

\section{Statistical analysis}

Cox proportional hazard regression models were fitted to the data with attained age as the time scale [11]. Participants were censored when any of the following events occurred after entry into the cohort: colorectal cancer, death, emigration or 31 December 2012. The hazard ratios (HRs) of cancer were estimated by calculating the HRs from the Cox regression models. We calculated the HR of colorectal cancer for each of the three quantiles of exposure to n-3/ n- 6 fatty acids by using the lowest quartile as a reference and intake level as a continuous variable. Energy adjustment was performed by the residual method. The p-trend was estimated by using the order of the quartile groups. The proportional hazards assumption was checked by graphs of scaled Schoenfeldt residuals versus time. The analyses for colon cancer and rectal cancer were conducted separately.

All tests of statistical hypotheses were done on the 2-sided $5 \%$ level of significance corresponding to the use of twosided $95 \%$ confidence intervals (CIs). No adjustment for multiple statistical tests was performed.

\section{Ethical statement}

All participants provided an informed consent to participate in the study and the study was approved by the Regio- 
Table 1. Characteristics of study population by omega-3 intake quartile at baseline

\begin{tabular}{|c|c|c|c|c|c|c|}
\hline \multirow[b]{2}{*}{ Characteristic } & \multirow[b]{2}{*}{$\begin{array}{c}\text { Entire } \\
\text { cohort } \\
\text { participants }\end{array}$} & \multicolumn{4}{|c|}{ Energy-adjusted omega-3 intake quartile (g/day) } & \multirow[b]{2}{*}{ p-value } \\
\hline & & $\begin{array}{c}\text { Quartile } 1 \\
\text { (lowest } \\
25 \% \text { ) } \\
0.12 \text { to }<1.08\end{array}$ & $\begin{array}{c}\text { Quartile } 2 \\
\text { (25th to } 50 \text { th } \\
\text { percentile) } \\
1.08 \text { to }<1.29\end{array}$ & $\begin{array}{c}\text { Quartile } 3 \\
\text { (50th to } 75 \text { th } \\
\text { percentile) } \\
1.29 \text { to }<1.57\end{array}$ & $\begin{array}{c}\text { Quartile } 4 \\
\text { (highest } \\
25 \% \text { ) } \\
1.57-22.66\end{array}$ & \\
\hline No. of participants & 48,223 & 12,056 & 12,055 & 12,056 & 12,056 & \\
\hline Age at enrollment (yr) & $39.7 \pm 5.7$ & $38.2 \pm 5.7$ & $39.0 \pm 5.7$ & $40.1 \pm 5.7$ & $41.4 \pm 5.5$ & $<0.001$ \\
\hline \multicolumn{7}{|l|}{ Body mass index $\left(\mathrm{kg} / \mathrm{m}^{2}\right)$} \\
\hline$<25$ & $33,639(69.8)$ & $8,391(69.6)$ & $8,611(71.4)$ & $8,521(70.7)$ & $8,116(67.3)$ & $<0.001$ \\
\hline $25-29$ & $10,098(20.9)$ & $2,484(20.6)$ & 2,393 (19.9) & $2,525(20.9)$ & $2,696(22.4)$ & \\
\hline$\geq 30$ & $2,675(5.5)$ & $677(5.6)$ & $649(5.4)$ & $610(5.1)$ & $739(6.1)$ & \\
\hline Missing & $1,811(3.8)$ & $504(4.2)$ & $402(3.3)$ & $400(3.3)$ & $505(4.2)$ & \\
\hline \multicolumn{7}{|l|}{ Education (yr) } \\
\hline$\leq 10$ & $14,129(29.3)$ & $3,111(25.8)$ & $3,200(26.5)$ & $3,575(29.7)$ & $4,243(35.2)$ & $<0.001$ \\
\hline $11-13$ & $18,513(38.4)$ & $4,843(40.2)$ & $4,805(39.9)$ & $4,552(37.8)$ & $4,313(35.8)$ & \\
\hline$>13$ & $14,639(30.4)$ & $3,901(32.4)$ & $3,831(31.8)$ & $3,693(30.6)$ & $3,214(26.7)$ & \\
\hline Missing & $942(2.0)$ & $201(1.7)$ & $219(1.8)$ & $236(2.0)$ & $286(2.4)$ & \\
\hline \multicolumn{7}{|l|}{ Smoking } \\
\hline Never & $19,525(40.5)$ & $5,001(41.5)$ & $5,018(41.6)$ & $5,061(42.0)$ & $4,445(36.9)$ & $<0.001$ \\
\hline Ever & $28,550(59.2)$ & $7,019(58.2)$ & $7,013(58.2)$ & $6,963(57.8)$ & $7,555(62.7)$ & \\
\hline Missing & $148(0.3)$ & $36(0.3)$ & $24(0.2)$ & $32(0.3)$ & $56(0.5)$ & \\
\hline \multicolumn{7}{|l|}{ Alcohol intake (g/day) } \\
\hline$<5$ & $36,192(75.1)$ & $9,116(75.6)$ & $8,969(74.4)$ & $9,060(75.1)$ & $9,047(75.0)$ & $<0.001$ \\
\hline $5-25$ & $11,822(24.5)$ & $2,852(23.7)$ & $3,029(25.1)$ & $2,956(24.5)$ & $2,985(24.8)$ & \\
\hline$\geq 25$ & $209(0.4)$ & $88(0.7)$ & $57(0.5)$ & $40(0.3)$ & $24(0.2)$ & \\
\hline Energy intake (kcal/day) & $1,555 \pm 452$ & $1,738 \pm 462$ & $1,666 \pm 416$ & $1,538 \pm 390$ & $1,280 \pm 396$ & $<0.001$ \\
\hline Colorectal cancer cases & 334 & 60 & 90 & 84 & 100 & \\
\hline Follow-up (yr) & $21.1 \pm 0.7$ & $21.1 \pm 0.6$ & $21.1 \pm 0.7$ & $21.1 \pm 0.6$ & $21.1 \pm 0.8$ & \\
\hline Cumulative follow-up (yr) & $1,018,700.7$ & $254,665.6$ & $254,589.0$ & $254,826.5$ & $254,619.6$ & \\
\hline
\end{tabular}

Values are presented as mean \pm standard deviation or number $(\%)$. p-values were calculated by chi-square test for categorical variables and ANOVA for continuous variables.

Table 2. Quartile distribution of omega-3 and -6 fatty acid of study population (g/day)

\begin{tabular}{|ccccc} 
Type & $\begin{array}{c}\text { Quartile } 1 \\
\text { (lowest }\end{array}$ & $\begin{array}{c}\text { Quartile } 2 \\
\text { (25th to } 50 \text { th } \\
\text { percentile) }\end{array}$ & $\begin{array}{c}\text { Quartile 3 } \\
\text { (50th to } 75 \text { th } \\
\text { percentile) }\end{array}$ & $\begin{array}{c}\text { Quartile } 4 \\
\text { (highest } \\
\text { 25\%) }\end{array}$ \\
\hline Omega-3 fatty acid & 0.12 to $<1.08$ & 1.08 to $<1.29$ & 1.29 to $<1.57$ & 1.57 to 22.66 \\
\hline Alpha-linolenic acid & 0.12 to $<0.84$ & 0.84 to $<0.98$ & 0.98 to $<1.16$ & 1.16 to 4.47 \\
\hline Docosapentaenoic acid & 0 to $<0.02$ & 0.02 to $<0.03$ & 0.03 to $<0.05$ & 0.05 to 1.34 \\
\hline Fish oil-derived omega-3 & 0 to $<0.12$ & 0.12 to $<0.22$ & 0.22 to $<0.39$ & 0.39 to 18.32 \\
\hline Eicosapentaenoic acid & 0 to $<0.03$ & 0.03 to $<0.07$ & 0.07 to $<0.13$ & 0.13 to 9.19 \\
\hline Docosahexaenoic acid & 0 to $<0.09$ & 0.09 to $<0.16$ & 0.16 to $<0.27$ & 0.27 to 11.28 \\
\hline Omega-6 fatty acid & 0.55 to $<4.32$ & 4.32 to $<4.86$ & 4.86 to $<5.45$ & 5.45 to 13.95 \\
\hline Linoleic acid & 0.55 to $<4.23$ & 4.23 to $<4.77$ & 4.77 to $<5.34$ & 5.34 to 13.95 \\
\hline Arachidonic acid & 0 to $<0.05$ & 0.05 to $<0.08$ & 0.08 to $<0.12$ & 0.12 to 1.49 \\
\hline
\end{tabular}


nal Ethics Committee in Uppsala and the Regional Ethics Committee at Karolinska Institutet, Stockholm (Dnr: 210-93, 1993; Dnr: 02-541, 2002).

\section{Results}

During a median of 21.3 years of follow-up, a total of 334 colorectal cancer cases were ascertained. Among them, 201 were colon cancer and 133 were rectal cancer. When the participants were categorized by total n-3 intake levels, the four groups showed differences in the distribution of age at enrollment, body mass index, smoking habits, alcohol intake amount, and total energy intake (Table 1). The quartile categories of n-3 and n-6 fatty acid intake are provided in Table 2. Fish-derived n-3 contributed to approximately $17 \%$ of the total n-3 fatty acid intake.

Table 3 shows the association between n-3/n-6 intake and colorectal cancer risk. There were no statistically significant associations between n-3 fatty acid intake and colorectal cancer risk. However, a high intake of n-6 fatty acids, especially linoleic acid, showed an increased risk for colorectal cancer (HR for the highest quartile, 1.40 [95\% CI, 1.02 to 1.92]; p-trend $=0.038)$. Stratified by anatomical subsites, the statistically significant association persisted only for rectal cancer. In addition, a high intake of fish-derived DHA intake was associated with a reduced risk of rectal cancer (HR for the third and highest quartiles compared to the lowest quantile, 0.59 [95\% CI, 0.37 to 0.96] and 0.62 [95\% CI, 0.39 to 0.98], respectively). All the models fit the proportional hazard assumption.

\section{Discussion}

In a large population-based cohort, we found little support for an association between fish-derived n-3 PUFAs and colorectal cancer.

Fish are the main dietary source of long-chain n-3 fatty acids, which have been suggested to play a protective role in colorectal cancer development. Although some studies have demonstrated an inverse relationship between fish consumption and colorectal cancer $[4,12,13]$, others have not found a clear association [14-16]. In line with previous meta-analyses and pooled analyses that did not find an inverse association between fish intake and colorectal cancer risk [17,18], a comprehensive review by the World Cancer Research Fund concluded that the association between fish and colorectal cancer is "limited-suggestive" [3]. In a recent study from the European Prospective Investigation into Cancer and Nutrition (EPIC) cohorts, the total intakes of fish, fatty fish and lean fish were associated with a reduced risk for colorectal cancer [19].

Previous studies applying subgroup analysis for subsites of colorectal cancer did not find a clear difference in the risk by subsites, although the pooled HR of fish intake for rectal cancer was slightly lower than the pooled HR for colon cancer (HR per $100 \mathrm{~g} /$ day increment: 0.84 [95\% CI, 0.69 to 1.02] for rectal cancer and 0.91 [ $95 \%$ CI, 0.80 to 1.03] for colon cancer) [3]. It has been suggested that subsites of colorectal cancer show different risk factor profiles due to differences in embryological origins, physiological function, fecal composition, bile acid metabolism, intestinal transit time, and metabolizing enzyme activity [20]. In our study, fish-derived omega-3 intake was associated with a reduced risk for rectal cancer in the highest intake group. Different susceptibilities to fish oil intake could be explained by more fermentation reactions in the proximal colon and higher concentrations of $\mathrm{N}$-nitroso compounds exposure markers, e.g., 6-O-methyldeoxyguanosine in the distal colon [2]. In addition, a recent microbiome study suggested that supplementation with krill oil resulted in differential effects on the microbial community at different gut locations in mice [21].

A variety of experimental studies and different clinical trials have substantiated the beneficial role of omega-3 PUFAs in preventing the pathogenesis of colorectal cancers [1]. Antineoplastic activity has been related to the regulatory effects exhibited by omega-3 PUFAs on cell proliferation and apoptosis [22]. Antiangiogenic and antimetastatic effects have also been reported for these fatty acids [22]. Other suggested mechanisms include the suppression of arachidonic acid-derived eicosanoid biosynthesis, which is related to altered immune response to cancer cells and inflammation, alteration of estrogen metabolism, and altering the production of free radicals and reactive oxygen species [1]. Finally, it has been suggested that omega-3 PUFAs may act as adjuvant therapeutic agents that sensitize tumors, including colon cancer, to different antineoplastic drugs $[23,24]$.

High intake of linoleic acid showed an increased risk for colorectal cancer in the current study. Although animal models suggest that n-6 fatty acids promote colorectal cancer [1], epidemiological evidence has not shown a conclusive association $[1,5]$. Therefore, the potential elevated risk of colorectal cancer among individuals with a high intake of n-6 fatty acids needs to be further elucidated in other prospective studies.

The major strengths of our study include the completeness of the follow-up in a large population-based sample and the relatively longer follow-up periods than other prospective studies, which allows us to assess the long-term effect of diet 


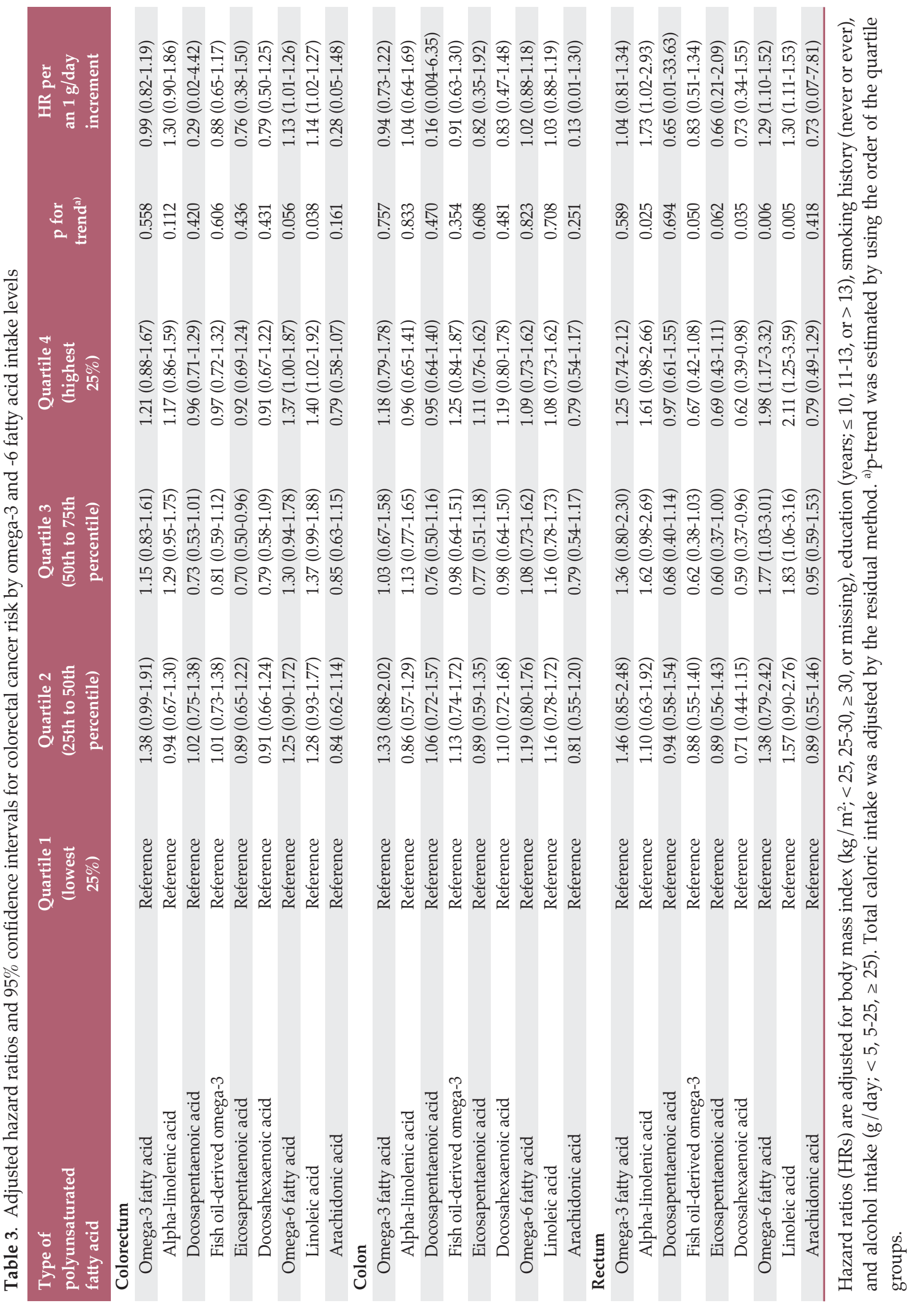


on cancer risk. However, the limitations of the current study include a lack of detailed information on fish cooking methods, fish oil supplementation use, and oils used for cooking and a lack of repeated measures of exposure, which could have resulted in residual confounding. Although information on the frequency of fish oil supplements and fried fish consumption was available, these variables could not be included as potential confounding variables due to the high proportion of missing data. Additionally, important protective factors, such as anti-inflammatory drug use and physical activity, could not be considered.

We cannot rule out that our results were due to chance alone. We observed two statistically significant results in our primary analyses consisting of 27 statistical tests; 1.35 could be expected by chance alone. The intake levels of fatty acids were approximately $50 \%$ of the Swedish national data from the National Food Administration [25]. These differences could result from the different dietary assessment methods, e.g., an FFQ was used for our study, whereas a dietary record was used for the national data. However, the underestimation of the intake levels is more likely to be nondifferential and therefore less likely to affect the results of the current study. In addition, the intake levels of our study are compa- rable with those of other Swedish studies [26] and the EPIC study [19], which used an FFQ for dietary assessment.

In conclusion, we did not find strong evidence that a high intake of fish-derived long-chain PUFAs may reduce the risk of colorectal cancer among Swedish women, although a marginally significant reduced risk for rectal cancer was observed.

\section{Conflicts of Interest}

Conflict of interest relevant to this article was not reported. Where authors are identified as personnel of the International Agency for Research on Cancer/World Health Organization, the authors alone are responsible for the views expressed in this article, and they do not necessarily represent the decisions, policy or views of the International Agency for Research on Cancer/World Health Organization.

\section{Acknowledgments}

This study was supported by Korea Research Foundation (2017R1A2B4009233).

\section{References}

1. Larsson SC, Kumlin M, Ingelman-Sundberg M, Wolk A. Dietary long-chain n-3 fatty acids for the prevention of cancer: a review of potential mechanisms. Am J Clin Nutr. 2004;79: 935-45.

2. Chen GC, Qin LQ, Lu DB, Han TM, Zheng Y, Xu GZ, et al. $\mathrm{N}-3$ polyunsaturated fatty acids intake and risk of colorectal cancer: meta-analysis of prospective studies. Cancer Causes Control. 2015;26:133-41.

3. World Cancer Research Fund/American Institute for Cancer Research. Diet, nutrition, physical activity and cancer: a global perspective. Continuous update project expert report 2018 [Internet]. London: World Cancer Research Fund; 2019 [cited 2019 Sep 10]. Available from: https:// dietandcancerreport.org.

4. Wu S, Feng B, Li K, Zhu X, Liang S, Liu X, et al. Fish consumption and colorectal cancer risk in humans: a systematic review and meta-analysis. Am J Med. 2012;125:551-9.

5. Song M, Chan AT, Fuchs CS, Ogino S, Hu FB, Mozaffarian D, et al. Dietary intake of fish, omega-3 and omega- 6 fatty acids and risk of colorectal cancer: a prospective study in U.S. men and women. Int J Cancer. 2014;135:2413-23.

6. Larsson SC, Rafter J, Holmberg L, Bergkvist L, Wolk A. Red meat consumption and risk of cancers of the proximal colon, distal colon and rectum: the Swedish Mammography Cohort. Int J Cancer. 2005;113:829-34.

7. Roswall N, Sandin S, Adami HO, Weiderpass E. Cohort pro- file: the Swedish Women's Lifestyle and Health cohort. Int J Epidemiol. 2017;46:e8.

8. Lof M, Sandin S, Lagiou P, Hilakivi-Clarke L, Trichopoulos D, Adami HO, et al. Dietary fat and breast cancer risk in the Swedish women's lifestyle and health cohort. Br J Cancer. 2007;97:1570-6.

9. Hedelin M, Lof M, Sandin S, Adami HO, Weiderpass E. Prospective study of dietary phytoestrogen intake and the risk of colorectal cancer. Nutr Cancer. 2016;68:388-95.

10. Shin A, Sandin S, Lof M, Margolis KL, Kim K, Couto E, et al. Alcohol consumption, body mass index and breast cancer risk by hormone receptor status: Women' Lifestyle and Health Study. BMC Cancer. 2015;15:881.

11. Korn EL, Graubard BI, Midthune D. Time-to-event analysis of longitudinal follow-up of a survey: choice of the time-scale. Am J Epidemiol. 1997;145:72-80.

12. Kato I, Akhmedkhanov A, Koenig K, Toniolo PG, Shore RE, Riboli E. Prospective study of diet and female colorectal cancer: the New York University Women's Health Study. Nutr Cancer. 1997;28:276-81.

13. Norat T, Bingham S, Ferrari P, Slimani N, Jenab M, Mazuir M, et al. Meat, fish, and colorectal cancer risk: the European Prospective Investigation into cancer and nutrition. J Natl Cancer Inst. 2005;97:906-16.

14. Engeset D, Andersen V, Hjartaker A, Lund E. Consumption 
of fish and risk of colon cancer in the Norwegian Women and Cancer (NOWAC) study. Br J Nutr. 2007;98:576-82.

15. Pham NM, Mizoue T, Tanaka K, Tsuji I, Tamakoshi A, Matsuo $\mathrm{K}$, et al. Fish consumption and colorectal cancer risk: an evaluation based on a systematic review of epidemiologic evidence among the Japanese population. Jpn J Clin Oncol. 2013;43:935-41.

16. Tiemersma EW, Kampman E, Bueno de Mesquita HB, Bunschoten A, van Schothorst EM, Kok FJ, et al. Meat consumption, cigarette smoking, and genetic susceptibility in the etiology of colorectal cancer: results from a Dutch prospective study. Cancer Causes Control. 2002;13:383-93.

17. Spencer EA, Key TJ, Appleby PN, Dahm CC, Keogh RH, Fentiman IS, et al. Meat, poultry and fish and risk of colorectal cancer: pooled analysis of data from the UK dietary cohort consortium. Cancer Causes Control. 2010;21:1417-25.

18. Yu XF, Zou J, Dong J. Fish consumption and risk of gastrointestinal cancers: a meta-analysis of cohort studies. World J Gastroenterol. 2014;20:15398-412.

19. Aglago EK, Huybrechts I, Murphy N, Casagrande C, Nicolas $\mathrm{G}$, Pischon T, et al. Consumption of fish and long-chain n-3 polyunsaturated fatty acids is associated with reduced risk of colorectal cancer in a large European cohort. Clin Gastroenterol Hepatol. 2020;18:654-66.

20. Shin A, Joo J, Bak J, Yang HR, Kim J, Park S, et al. Site-specific risk factors for colorectal cancer in a Korean population. PLoS
One. 2011;6:e23196.

21. Lu C, Sun T, Li Y, Zhang D, Zhou J, Su X. Microbial diversity and composition in different gut locations of hyperlipidemic mice receiving krill oil. Appl Microbiol Biotechnol. 2018;102: 355-66.

22. Iigo M, Nakagawa T, Ishikawa C, Iwahori Y, Asamoto M, Yazawa $\mathrm{K}$, et al. Inhibitory effects of docosahexaenoic acid on colon carcinoma 26 metastasis to the lung. Br J Cancer. 1997; 75:650-5.

23. Cha MC, Lin A, Meckling KA. Low dose docosahexaenoic acid protects normal colonic epithelial cells from araC toxicity. BMC Pharmacol. 2005;5:7.

24. Gomez de Segura IA, Valderrabano S, Vazquez I, Vallejo-Cremades MT, Gomez-Garcia L, Sanchez M, et al. Protective effects of dietary enrichment with docosahexaenoic acid plus protein in 5-fluorouracil-induced intestinal injury in the rat. Eur J Gastroenterol Hepatol. 2004;16:479-85.

25. Livsmedelsverket: Swedish Food Agency. Riksmaten 2010 [Internet]. Uppsala: Swedish Food Agency; 2012 [cited 2019 Sep 10]. Available from: https://www.livsmedelsverket.se/ matvanor-halsa--miljo/ kostrad-och-matvanor / matvanor--undersokningar/riksmaten-2010-11---vuxna.

26. Terry P, Bergkvist L, Holmberg L, Wolk A. No association between fat and fatty acids intake and risk of colorectal cancer. Cancer Epidemiol Biomarkers Prev. 2001;10:913-4. 